\title{
The meaning of style
}

\author{
Penelope Eckert \\ Stanford University
}

In his groundbreaking study of Martha's Vineyard, William Labov (Labov 1963) showed that phonological variables can take on very textured local meanings. The use of a raised nucleus in /ay/, commonly referred to as "Canadian Raising" is recognized all along the Atlantic coast as characteristic of various island dialects (Wolfram and Schilling-Estes 1996). In recent generations, the nucleus of this diphthong has been lowering to [a], presumably under the influence of the lowered variant that predominates in the mainland US and that characterizes mainstream US English. Labov's study found that the height of this nucleus was functioning as a symbolic resource in the struggle over the fate of the island. In the process, the height of the nucleus in /ay/ had taken on quite specific local meaning. It is on the nature of such meaning, and the mechanisms by which it is constructed, that I wish to focus in the following pages.

When Labov arrived on Martha's Vineyard, a growing tourist and summer home trade was bringing about major changes in the island's life and economy, and the island's inhabitants were split over the desirability of this mainland incursion. On the one hand, people engaged in the local fishing economy, dominated by old island families of English stock, saw this as a serious threat to local control of the island's life and economy. Some others saw the summer trade as an opportunity for themselves and for the island's viability more generally. The issue of mainland control vs. the traditional island culture, then, was a central ideological struggle in the local community. This was not a struggle between the mainland and the island so much as a struggle among islanders with respect to their relation to the mainland. Labov showed that the pronunciation of /ay/ had been appropriated as a symbolic resource in this struggle, as lowering of the nucleus came to be associated not simply with the mainland but with the local implications of a mainland orientation. Those engaged in the local fishing community, and youngsters who planned to remain on the island for their adulthoods, were resisting - and reversing - this lowering and showed a high rate of nucleus raising. The height of the nucleus, then, originally marking a geographic difference, became symbolic of a very local ideological struggle. Lowered /ay/ meant not simply 'mainland', but an ideological package created by the local struggle over mainland incursion.

It is probable that the height of the nucleus of /ay/ was never neutral. The mainland and the island have been in contact, and distinct, for as long as Europeans have been in both places. And as long as the pronunciation of /ay/ has been different in the two places, it has no doubt carried meaning associated with people's perception of the cultural differences between island and mainland. And this is where the study of the meaning of variation must begin. Whenever a linguistic difference becomes distinctive, the terms of this distinction are based in the social relations that surround it. Put differently, language difference can be called into service in the construction of social distinctions. People living far enough from the eastern seaboard to only know that islanders have a peculiar pronunciation of /ay/ may simply see this as a regionalism. But anyone within the area will have a "take" on the differences between mainlanders and islanders. And for them, the social meaning of the pronunciation of /ay/ will be based in that take. If they think the islanders are quaint, they will hear the raised nucleus as quaint; if they think they're dour, chances are they will hear the raised nucleus as dour. It is important to note that this characterization places the viewer as well as the viewed. Seeing islanders as quaint makes the mainlander feel sophisticated; seeing them as dour makes the mainlander feel good-hearted. The vowel itself is heard as quaint or dour, and as a natural outcome of the islanders' quaintness or dourness. This is the process that Judith Irvine and Sue Gal refer to as iconization (Irvine and Gal 2000). It is in the day-to-day give and take of social practice that 
communities come to construct a shared take on themselves, on others, and on the differences between them. As long as an aggregate of people have no particular reason to set themselves off from others, there will be little attention to what they have in common, and in contradistinction from others. When circumstances and events create an interest in difference, though, that difference can be constructed out of a variety of material, including small linguistic differences. And as the circumstances and events become sufficiently foregrounded, the social meaning of a variable may become quite specific.

It is also quite probable that /ay/ was not the only linguistic resource that people called upon in the Martha's Vineyard fray. Labov also examines its partner diphthong/aw/, which shows a somewhat different, but clearly related, distribution. And there were no doubt other resources - ways of speaking of those who were pushing the resistance probably ranged from characteristic lexical items to discourse markers and speech activities. In other words, the significance of /ay/ raising was no doubt embedded in a more general style, including clothing, movement, territory and leisure activities, that said something like "English stock fisherfolk". And it is probable that people on the island, standing in a variety of positions with respect to these political issues, showed some variability in the ways in which they selected, combined, and situationally deployed these stylistic resources.

In other words, the meaning of variation lies in its role in the construction of styles, and what I am proposing here is a study of the role of variation in stylistic practice. This involves not simply placing variables in styles, but in understanding this placement as an integral part of the construction of social meaning. This has several implications for our view of variation. First, variables do not come into a style with a specific, fixed, meaning, but take on such meaning in the process of construction of the style. This leads to the second point, that style (like language) is not a thing but a practice. It is the activity in which people create social meaning, as style is the visible manifestation of social meaning. And inasmuch as social meaning is not static, neither are styles ${ }^{1}$. Stylistic practice involves a process of bricolage, by which people combine a range of existing resources to construct new meanings or new twists on old meanings (Hebdige 1984). Small stylistic moves, such as the addition of a Mickey Mouse watch to a business ensemble, can tweak an already-existing style and the persona that it presents - in this case perhaps inserting a zest of playfulness. The tweaking, however, is not just about the tweaker, but adjusts the social world around the tweaker. Perhaps the businesswoman wearing a Mickey Mouse watch to a meeting wishes to convey a certain amount of liveliness and independence - not just for the fun of it, but more likely in order to distinguish herself from those that she sees as stodgy and uninteresting. And the nature of this stodginess is specific to the community in which she wears business clothing - it is probably not aimed at her boorish grandfather, but at her colleagues' office or business practices. And with this stylistic act, she puts the distinction on the table for all to see ${ }^{2}$.

The selection of variables for making stylistic moves is based, then, in the speaker's interpretation of the meaning potential of the available resources. The mainland-island separation, and the dialect differences that go with that separation, make /ay/ and /aw/ prime linguistic resources for building styles that embed that separation in some way. The general mainland-island significance of nucleus height in /ay/ is vivified locally by the foregrounding of current social issues. At another time, in other words, the issues associated with island-mainland difference may have been quite different, and speakers may have deployed /ay/ in very different ways. One has only to look at the way that features of African American Vernacular English were deployed in the minstrel tradition and comedy such as Amos ' $n$ Andy, evoking a benign, shuffling, inept and foolish stereotype (Rickford and Rickford 2000), and contrast this with the more recent white adolescent use of AAVE features to lay claim to coolness (Bucholtz 1999). In these two eras, African American linguistic features have served as very different stylistic resources. In other words, the use of a stylistic resource affects not only the receiving style, but the resource itself, feeding back into discourses of race, ethnicity, class, etc. One might consider, for example, that the use of Chicano features in

\footnotetext{
${ }^{1}$ Some styles (e.g. corporate male style) depend on an appearance of stability. One could say that they resist change, but I am inclined to say that they actively maintain stasis. Every time a corporate man buys a tie he aligns himself with respect to a range of ideologies, and the selection of a conservative one is as much a stylistic move as the selection of one with naked women or palm trees.

${ }^{2}$ Of course, the move may backfire, as those around her can interpret the watch as they see fit, and this is where power enters into one's ability to make meaningful moves - hence to make meaning.
} 
the Southwest that Jane Hill (Hill 1993) discusses has the effect of constructing Chicano features - and their speakers - as a comic population. Stylistic resources, whether features of racialized dialects or of geographically defined dialects, come with a meaning potential that becomes more precise in the local context.

The study of social meaning in variation, then, needs to trace two kinds of patterns - what /ay/ raising offers as potential meanings by virtue of its larger distribution (e.g. across the eastern seaboard - and in the opposition between mainland and island), and how it comes to be deployed locally and combined with other resources, to constitute a "fisherfolk" style.

Things in the world become stylistic resources by virtue of their place in local discourse - in the collaborative work of sense-making. While individuals make stylistic moves, such as wearing a Mickey Mouse watch, they do so in cooperation with, or with reference to, the people around them. Since a stylistic move is to be put out into a community for the purpose of being interpreted, speakers select resources on the basis of their potential comprehensibility in that community. This does not mean that people select only resources that will be comprehensible, since certain styles may call for some mystification. James Ferguson, in his study of the deployment of style in the Zambian Copperbelt (Ferguson 1999), notes that lack of interpretability is key to a cosmopolitan style. But the uninterpretability itself is invoked because it is interpretable on a meta level - the cosmopolitan is precisely someone who is supposed to have access to knowledge and resources that are locally inaccessible. And the Copperbelt cosmopolitan no doubt reaches out for resources that are mystifying but not random or off-the-wall.

I have argued elsewhere (Eckert 2000; Eckert and McConnell-Ginet 2003) that the community of practice (Lave and Wenger 1991; Wenger 2000) is a prime locus of stylistic construction. Every speaker participates in a variety of communities of practice, or collections of people who engage together in a particular enterprise - a garage band, a family, a gang, a car pool, an office. The community looks out jointly on the social landscape, interpreting the landscape, and constructing their place and stance within that landscape. And individuals' place in the community is closely related to their participation in that process of construction. An important part of this meaning-making is the social characterization and evaluation of people and groups out in that landscape, and of their stylistic practices. It is in this process of meaning-making that speakers assign meaning to stylistic resources, and assess them as potential resources for their own stylistic moves.

Stylistic practice, then, involves adapting linguistic variables available out in the larger world to the construction of social meaning on a local level. The association of Mickey Mouse watches with children and playfulness does not in and of itself predict that a businesswoman will wear it to work. But in doing so, that businesswoman transforms the watch into an expression of independence within the business context. I am advocating, therefore, a study of variation that traces the path of a variable from its general state of availability to its specific deployment. Ultimately, this means that one might begin with a style, tracing the contributions of individual resources to that style. This is a reversal of the traditional approach to variation, which focuses on variables in virtue of their role in the dialect system or in linguistic change in progress.

\section{Style in Sociolinguistic Variation}

The picture I am offering of style and of the social meaning of variation is a fairly radical departure from established practice in the field of variation (and it is certainly not intended as a challenge to that practice, but as an extension of it). The early and groundbreaking studies of variation, seeking patterns of variation across large populations (Labov 1966; Wolfram 1969; Trudgill 1974), focused on correlations of linguistic variables with the broad demographic categories of class, age and gender. From this tradition there emerged a view of social meaning as directly associated with - even determined by - these categories. Thus, it has been common to view variables as marking membership in, or affiliation with, class and gender categories (and to view age differences as representing apparent time). But these broad demographic patterns are as much the result as the source of social meaning in variation, and understanding them requires that we explore the relation between local meaning and these larger distributions. 
The predominant approach to style in variation has focused on a continuum of casualness and formality. Introduced by William Labov in his study of New York City (Labov 1966), this view of style allowed Labov to locate intra-speaker variation seamlessly in the broader patterns of variation across large communities. It quite explicitly located stylistic variation in the speaker's class position. The class stratification of linguistic variables assigned prestige to the speech at the upper end and stigma to the speech at the lower end. Prestige and stigma, then, have come to be the primary social meanings associated with variables, and formality brings a focus on prestige and an attempt to avoid stigma. With social meaning located in demographic categories, stylistic agency emerged in variation studies as a means of tempering one's appearance of category membership. It is important to consider that Labov's emphasis, though, particularly in subsequent writing (Labov 2000), has been not on social meaning but on attention paid to speech, so that the importance of casualness and formality lies in their effect on speakers' selfmonitoring - hence on their ability to avoid stigma.

This view of style has not gone unchallenged. Most notably, Allan Bell (Bell 1984) challenged attention paid to speech as underlying stylistic variation, arguing that it is a mediating variable and that we need to ask what in the situations is causing speakers to pay more or less attention ${ }^{3}$. His answer to the question is that speakers shift styles as accommodation to their audience - primarily their addressee. He argues, further, that shifts in style as a function of topic are due to an association of topics with particular audiences. In Bell's recent expansion of his theory (Bell 2001), he argues further that a speaker's spontaneous adoption of a style (i.e. not in response to topic or present audience) is done with an audience in mind. This is tantamount to saying that the speaker's identity is embedded in social relations, which is clearly true. But it also suggests that the speaker is focusing on a specific imagined audience, and limits the speaker's agency to adaptation to pre-existing styles and social categories. This is a serious limitation that does not allow for creativity and change.

Nik Coupland (Coupland 1980; Coupland 1985; Coupland 2000) provided an early exploration of the use of variation to construct personae. His study of a disc jockey on Cardiff radio (Coupland 2000) shows a speaker using a variety of dialect features, calling on a variety of social meanings, as he moves around a complex social space. His strategic use of a range of dialect features yields a fluid persona rather than an adaptation to static types. Variation, in this case, is a resource for calling on a variety of places in social space, reminiscent of the acts of identity described by Le Page and Tabouret-Keller (LePage and TabouretKeller 1985). Where Labov's treatment of style focuses on the vertical axis of social class, the work of Bell and Coupland brings in the horizontal. Coupland, furthermore, argues that stylistic practice involves not simply the use of native variables, but brings in resources beyond one's own native dialect. The disc jockey's use of Cardiff features reaches out into the social landscape, and assigns meanings to these features based on commonly-held views of their socio-geographical significance.

Before I move on to discuss this process of meaning-assignment further, I would like to come back to the relation between the axis of formality that dominates Labov's view of style, and the personaconstruction view that I am exploring here. John Fischer, in the first quantitative study of variation (Fischer 1958), examined some schoolchildren's use of the suffix -ing, and found several interesting correlations. He found that boys reduced -ing more than girls, that more roustabout ('typical') boys reduced -ing more overall than boys who were teachers' pets. Finally, he found that all boys reduced -ing less in interviews than in conversation. One can argue that -ing is a stigmatized variant and that boys avoid stigma less than girls, and roustabout boys even less than teachers' pets, and that everyone is avoiding stigma when speaking with adults. However, it is hard to view reduced -ing on its own as stigmatized. While certain styles making extreme use of reduction may be stigmatized in the judgment of some hearers, this variant is not in itself stigmatized and is, in fact, generally quite well-received when an upper middle class speaker is acting casual and friendly. Such a speaker would be less likely to use negative concord or (in the case of a New Yorker) an extremely raised /aeh/ or a stop variant for /th/to this purpose. The general meaning of -ing reduction around the English-speaking world, though, is 'informal' and the use of this variant will only be stigmatized where informality is viewed as inappropriate. An informal style may be seen as

\footnotetext{
${ }^{3}$ I believe that this is inherent in Labov's account, and that he intends attention paid to speech to be the cognitive consequence of situations, which in turn runs the process of variation. In other words, a casual situation, or fear, or distraction, leads a speaker to lose control of speech, and what emerges with this loss of control is the vernacular.
} 
insolent, even threatening under certain circumstances. The frequent reduction of -ing probably contributed to a devil-may-care style among Fisher's roustabout boys. In interviews with adults, kids are no doubt being more formal, but one might consider that in their formality, they (or at least the roustabout boys) are also pulling back on the devil-may-care self-presentation.

Then what is the meaning of formality? Judith Irvine (Irvine 1979) has pointed out that the use of the notion of formality in the study of language has touched on several dimensions. For instance, formality can be related to seriousness, or unfamiliarity, or social distance, or deference. While multiples of these commonly co-occur, we can no longer afford to conflate them if we are to focus on meaning in variation. Seriousness itself can include gravity, earnestness, concern with important matters. And indeed, speaking formally can confer gravity or importance on situations and topics. A speaker may manage style in an effort to sound more formal in particular ways - to present oneself as a serious person, to show that one takes the subject matter seriously, to show respect or deference to another, to call upon a positional, public identity, to create distance. While these all merge to some extent in the kinds of interactions found in sociolinguistic interviews, in day-to-day life they may not.

\section{Stylistic Practice and the Meanings of Variables}

Common practice views variables as directly indexing social categories, hence it is not uncommon to refer to sound changes that women lead in as "women's changes", and for divergence between male and female speech to be attributed to men's avoidance of sounding like women. It is particularly common for this kind of attribution to emerge in discussions of gender. In a similar spirit, the Japanese press has accused Japanese teenage girls who use assertive forms normally associated with male speech of trying to speak like men. In fact, the "like women" or "like men" refers not to women and men so much as to characteristics associated with women and men - characteristics that are commonly judged undesirable in the other gender. In fact, Japanese girls using assertive forms are not trying to be boys, but to be assertive. This assertiveness, in turn, is part of a very female teenage trendy style (Okamoto 1995). In other words, linguistic choices index such things as attitudes, stances, and activities that in turn are associated with social categories. Variables index these categories indirectly (Silverstein 1976; Ochs 1991). It is this indirect nature of the relation between variables and categories that allows variation to be a resource not simply for the indexing of place in the social matrix but for the construction of new places and of nuanced social meanings.

My own work in Detroit suburban high schools (Eckert 1989; Eckert 2000) was designed to get at the local meaning of class for adolescents. After all, the class categories upon which sociolinguists had theorized the social dynamics for the spread of change were adult categories, and their components educational attainment, occupation, income - are still in the future for most adolescents. In an effort to understand how class is experienced in adolescence, I embarked on an ethnography in a high school and found that class is mediated in the high school by categories that re-cast class in the immediate school context. These categories lean heavily on style. In fact, style - in dress, in demeanor, in activity choice as well as in language - is central to the construction of social categories and meaning. In predominantly white schools around the Detroit area (and with variations across the US) there is a polarization between two opposed, class-based social categories. On the one hand, there are jocks, kids who base their social lives in the school institution, participating in the extracurricular and college-prep sphere, and constituting a middle class culture. In opposition to the jocks are the burnouts, a working class culture who reject the school as a locus of social life and activity, maintaining neighborhood ties and orienting to the urban area where they seek both stimulation and their working future.

It took no time to see that there was a major social opposition among the students - from the moment I walked into the school the opposition was clearly visible. What I later came to know were jocks were hanging around the student activities areas at lunchtime, wearing pastel colors, preppy styles, candycolored makeup and feathered hair (the girls, anyway), and school jackets. What I came to recognize as burnouts were hanging out in the school smoking area, wearing dark colors, rock concert tees, dark eye makeup and long straight hair (the girls), jeans jackets or Detroit and auto factory jackets, and wallet chains (the boys). Variation does a tremendous amount of symbolic work, but language does not work on its own and no linguistic variant works on its own. First of all, language is part of a broader semiotic system that 
includes such things as clothing, territory, musical taste, activities, and stances. The burnouts' urban orientation emerges in the use of symbols of street smarts such as wallet chains, symbols of urban affiliation such as Detroit jackets and auto factory jackets. Their claim to engagement in the realities of life outside of school shows up in symbols of toughness (e.g. leather jackets, wristbands or boots with studs), and in dark-colored clothing. There is a seamless relation between these visual symbols and the burnouts' use of urban variants of the late stages of the Northern Cities shift. The backing of /e/, and /uh/, and the raising of the nucleus of /ay/ (Eckert 2000) are all changes that are apparently progressing outward to the suburbs from the urban area, and the burnouts are the primary carriers of these changes. As shown in Figure 1, burnouts show a consistent lead over jocks in the use of advanced variants of these changes. Burnouts' rejection of the standardizing school institution emerges in evading school authority in a variety of ways, the flaunting of controlled substances, the refusal to use lockers and the cafeteria - and the use of negative concord. The jocks, meanwhile, offer a "clean cut" image including symbols of institutional affiliation such as decorating their lockers, wearing school jackets, and using standard grammar. Their institutional orientation includes an anti-urban orientation, which shows up in not only an avoidance of urban phonological variables, but in some cases a reversal of the urban changes that the burnouts lead in (the lowering of /e/ and the fronting of /uh/).

Figure 1. Varbrul factor weights for use of urban sound changes and negative concord, by gender and social category.

\begin{tabular}{|l|l|l|l|l|l|l|}
\hline & Girls & Boys & Burnouts & Jocks & Input & Sig. \\
\hline /uh/ & n.s. & n.s. & .571 & .437 & .494 & .000 \\
\hline /e/ & n.s. & n.s. & .540 & .467 & .262 & .016 \\
\hline /ay/ & .586 & .434 & .707 & .257 & .009 & .045 \\
\hline neg. concord & .412 & .567 & .708 & .306 & .238 & .000 \\
\hline
\end{tabular}

Of course jock and burnout styles can be seen as fairly stable combinations of variables, and one could accord these variables the meanings of "jock" and "burnout." However, the jocks and the burnouts account for at most half of the student population of the school. The rest of the student population is quite heterogeneous, but nonetheless dominated by the hegemonic jock-burnout opposition. Thus, those who are not jocks or burnouts refer to themselves as "in-betweens" and describe themselves in relation to their distance from jocks and/or burnouts, or the characteristics they share with one or the other category. And for this entire cohort, the use of variables is related to individuals' navigation of the broader semiotic space. Most notably, if we look at the larger student body, we find that the use of urban vowel shifts is associated with urban orientation more broadly. Thus, as shown in Table 1, the kids in the school who spend leisure time "cruising" Detroit, whether jock, burnout or in-between, show a significantly higher use of urban variables than those who do not.

Table 1. Relation between use of urban variables and participation in cruising among white Detroit suburban adolescents. (Eckert 2000)

\begin{tabular}{|l|l|l|l|l|}
\hline & Cruisers & Non-Cruisers & input & sig \\
\hline (uh) backing & .563 & .458 & .422 & .000 \\
\hline (e) backing & .544 & .464 & .331 & .029 \\
\hline (ay) raising & .765 & .381 & .011 & .000 \\
\hline $\begin{array}{l}\text { negative } \\
\text { concord }\end{array}$ & .777 & .294 & .106 & .000 \\
\hline
\end{tabular}

Other subtle personal differences show up in the distinct usage of different friendship groups, or network clusters, within and across social categories. Not all burnouts are alike, for example. Among the burnout girls, there are two main friendship clusters - the larger group who consider themselves "regular" or "normal" burnouts. These girls' identification as burnouts is based primarily in their working class orientation and their anti-school stance. While they are regularly at odds with authority for such things as 
skipping school, illegal substance use and a general rejection of adult intervention in their personal lives, they do not get into serious trouble. In contrast, a somewhat smaller cluster of girls pride themselves in being "the biggest burnouts" - I have heard "regular" burnouts refer to them as "burned-out burnouts". These girls are more wild, and pride themselves on coming to school stoned on a regular basis, being in serious academic trouble, staying out all night and getting in trouble with the police. There are also different kinds of girls involved in school activities - the "squeaky-clean" jocks, and a group of girls who participate enthusiastically in school activities, but who also like to "party" and some of whom have experimented with soft drugs. These girls are sometimes referred to as "partying jocks." Finally, there is a cluster of girls who participate in many school activities, but who eschew what they view as the jocks' popularity orientation. They consider themselves more down to earth, and many of themselves consider themselves more serious. Figure 2 shows the use of negative concord across these five network clusters from the wild girls, or the burned-out burnouts at the vernacular extreme, through the more serious girls at the most standard extreme. As this figure shows, the percentage of use of negative concord is a delicate indication of one's engagement in the standard institutional culture.

Figure 2. Relation between negative concord and girls' network cluster.

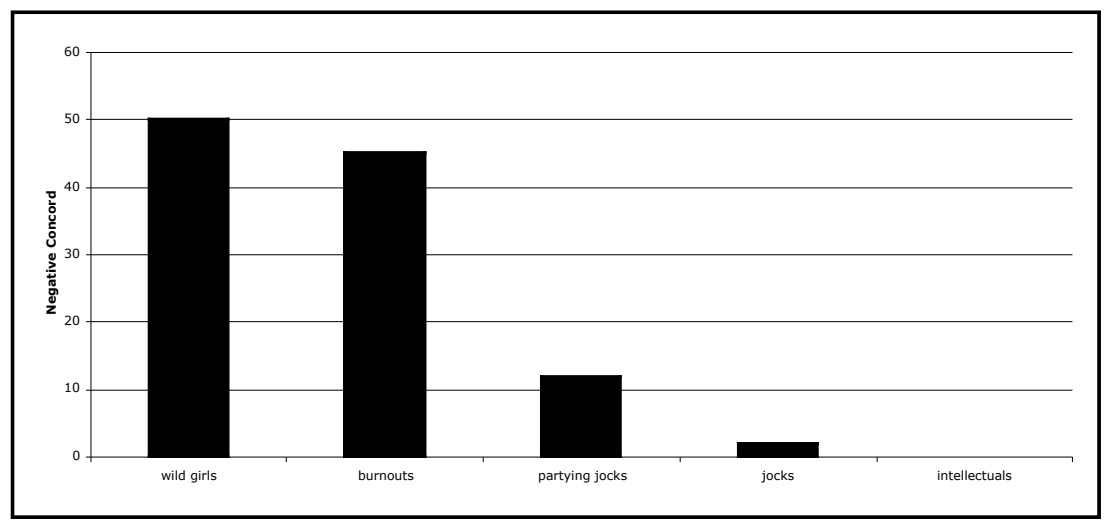

Qing Zhang has taken the view of variables as stylistic resources a major step further, showing that variation can be a key resource for the forging of new categories and the identities with which categories are co-constructed. Zhang (Zhang 2001) examined the speech of two kinds of managers in business in Beijing - managers in traditional state-owned business, and managers in the new foreign-owned businesses. The latter are part of a new and growing young elite, often referred to as "Chinese yuppies." The yuppies' engagement in the international market, including their engagement with non-mainland Chinese, pulls them into a cosmopolitan milieu and requires the production of a cosmopolitan persona. They are pioneering a materialistic and cosmopolitan life style in Beijing, and in doing so setting themselves quite apart from their peers in state-owned businesses. In addition to the active construction of "life style" through the consumption of home furnishings, clothing, toys and leisure activities - or one might say, to go with these the yuppies are developing a new and distinctive speech style. Perhaps the most salient resource in this linguistic construction is the use of the full tone, which is a feature of non-mainland Mandarin. This variable, completely foreign to Beijing and never appearing in the speech of the managers in state-owned businesses, brings a very clear cosmopolitan quality to their speech. Zhang emphasizes that the speakers are not imitating Hong Kong speech, but calling on a Hong Kong feature to bring Beijing into the transnational sphere. This is accomplished, furthermore, with the selective use of more local features.

Zhang went on to delve into the construction of meaning in local Beijing variables: rhotacization, lenition and the interdental pronunciation of $/ \mathrm{z} /$, all of which are quite saliently associated with Beijing Mandarin. She traced the meanings of these variables to salient personae in Beijing culture - personae that appear commonly in modern literature: the "alley saunterer" and the "smooth operator" - quite distinct male urban personae. She shows that the yuppies selectively adopt (or reject) these variables as a function 
of the nature of the personae they are developing. Women avoid both the smooth operator and the alley saunterer variables, as neither of these character types is useful to a business woman. The men, on the other hand, reject the alley saunterer variable as reflecting a character who is too feckless for a transnational businessman, but adopt a moderate amount of the smooth operator variable. The yuppies, thus, recombine locally available resources to construct a new, cosmopolitan - yet sitill Beijing - persona. On the other hand, the managers in state-owned businesses, still linked to local networks, continue to use a high level of Beijing features, and never use full tone.

\section{New Variables}

Growing out of dialectology on the one hand, and historical linguistics on the other, the study of variation has focused on variables in virtue of their status as regional markers or as interesting sound changes in progress. A couple of "stable" variables -ing and /th/ and /dh/ have also been studied - almost as touchstones of style and class. Otherwise, the net has not been cast very wide. A particularly interesting stable variable is the release of word-final stops. We're all aware of our use of t-release - and even aspiration - when we're being emphatic: "I did not't", or when we're being exaggeratedly precise particularly when we're annoyed at someone's failure to follow: "/a/ is not ${ }^{\mathrm{h}}$ a consonant". We're also

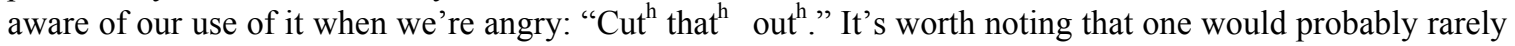
release all the occurrences in this latter utterance, but the release of the /t/ in that, and then the release in cut signals a continuous increase in the level of anger or annoyance. /t/ also gets released in academic styles. So where does $/ \mathrm{t} /$ release get its meaning? British speakers of English regularly release their $/ \mathrm{t} / \mathrm{s}$, and Americans adopt this feature when imitating British English . The age-old stereotype of the British, and British English, as superior, intelligent and educated, is no doubt at work here. A distinction made at the international level, then, seems to be providing American speakers with a resource for signaling superiority of a variety of sorts, but it seems to be primarily limited to intelligence, education, articulateness. Mary Bucholtz (Bucholtz 1996) has noted the use of this variable by a group of high school girls fashioning themselves as geeks. These girls saw themselves as intelligent - not as goody-goody good students, but as smarter than their teachers. Their use of / $t /$ release was a prominent resource in their development of a distinctive "intellectual" verbal style. $/ \mathrm{t} /$ release is also often heard as Jewish, and particularly as Orthodox. Sarah Benor (Benor 2002) examined this variable in a study of kids in an Orthodox community, and found that it indexed masculinity, inasmuch as masculinity is tied with Talmudic study. Further, she found that among both boys and girls - those who had been to Yeshiva released /t/ more than those who had not. In addition, she has shown nice anecdotal evidence of the use of this variable in interaction, as boys release /t/ when they're making a point in Talmudic discussion.

At the same time, /t/ release has also been identified as a feature of gay speech. In a study of a radio debate between a gay-identified lawyer and a straight-identified lawyer, Kathryn Campbell-Kibler, Sarah Roberts and Robert Podesva found that the gay lawyer indeed released more /t/ than his opponent. Reluctant to subscribe to a monolithic view of "gay" speech, Podesva has continued this work in a study of gay professionals as they adjust their style moving from more to less saliently gay situations. Comparing the language of a medical student, in the clinic with patients and at a barbecue with his friends, Podesva found a subtle pattern in the use of $/ \mathrm{t} /$ release. The medical student, Heath, adopts a highly competent and educated persona in the clinic, but a playful "bitchy diva" persona among his friends at the barbecue. As it turns out, he uses significantly more /t/ release in the clinic than at the barbecue, in keeping with the meaning of preciseness, intelligence and education that one would certainly want to evoke when functioning as a physician. At the barbecue, however, the bursts of the / $t /$ releases are rarer but significantly longer. This offers a wholly new view of the nature of variables. Podesva's interpretation of this is that the long burst is a particular way of exaggerating / $t$ / release, and that what is being conveyed is a kind of fussy hyper-articulateness, to the point of prissiness. In other words, the exaggerated release is intended not to convey intelligence, but prissiness - in keeping with the "bitchy diva" persona that Heath enjoys performing with his friends.

It should not be ignored that until these people studied / $t /$ release, the only time linguists had paid attention to word-final stops is in the study of cluster reduction in AAVE. Are these independent linguistic facts? Probably not entirely. While cluster reduction in AAVE may be historically unrelated to unreleased /t/ in Standard American English, the presence or absence of word-final / $t /$ is highly salient in the social 
evaluation of the speech of African Americans. Andrea Kortenhoven (pc) reports that her group of African American friends in high school had a special stylistic feature, the use of antyways for anyway. Seen as school-teachery talk, this insertion of consonants was no doubt in recognition of the distinctiveness between standard English and AAVE. Sensitivity to / $t /$ release, then, seems to permeate US language ideology and offer material for the construction of local stylistic features. Building on the large-scale opposition between British and American English, combined with the historic construction of Americans as rough upstarts in opposition to the refined and educated British, /t/ release provides a global resource that can, in turn, be put to local use. The precise meaning of $/ \mathrm{t} /$ release in actual use depends on the particular style - Orthodox Jew (learned), California geek girl (smart), bitchy diva (prissy) - that it's incorporated into.

\section{Conclusion}

Sociolinguistic variation is a central means by which the social is embedded in language. To understand how variation works, we have to concern ourselves with the nature of the social meaning it carries, and the mechanisms by which variation comes to be endowed with meaning. Most particularly, we need to examine the use of variation up close, to understand how (and to what extent) it is used to express very local and personal meanings. To do this, we have to focus on the role of variation in constructing personae - to see how people deploy linguistic resources to create styles. This paper has argued for an approach to variation that begins with style and works down to individual variables, and one that begins with the potential social meanings of variables and works down to the unfolding of those meanings in styles.

\section{References}

Bell, A. (1984). "Language Style as Audience Design." Language in Society 13: 145-204.

Bell, A. (2001). Back in style: Reworking audience design. Style and sociolinguistic variation. P. Eckert and J. R. Rickford. Cambridge, Cambridge University Press: 139-69.

Benor, S. (2002). "Sounding learned: The gendered use of /t/ in Orthodox Jewish English." Penn working papers in linguistics: Selected papers from NWAV 2000.

Bucholtz, M. (1996). Geek the girl: Language, femininity and female nerds. Gender and belief systems. N. Warner, J. Ahlers, L. Bilmeset al. Berkeley, Berkeley Women and Language Group: 119-131.

Bucholtz, M. (1999). "You da man: Narrating the raacial other in the production of white masculinity." Journal of sociolinguistics 3(4): 443-60.

Coupland, N. (1980). "Style-Shifting in a Cardiff Work Setting." Language in Society 9(1): 1-12.

Coupland, N. (1985). "'Hark, Hark, the Lark': Social Motivations for Phonological Style-Shifting." Language and Communication 5: 153-71.

Coupland, N. (2000). Language, situation and the relational self: Theorizing dialect-style in sociolinguistics. Stylistic variation in language. P. Eckert and J. Rickford. Cambridge, Cambridge University Press.

Eckert, P. (1989). Jocks and Burnouts: Social Categories and Identity in the High School. New York, Teachers College Press.

Eckert, P. (2000). Linguistic Variation as Social Practice. Oxford, Blackwell.

Eckert, P. and S. McConnell-Ginet (2003). Language and Gender. Cambridge, Cambridge University Press.

Ferguson, J. (1999). Expectations of Modernity: Myths and meanigns of urban life on the Zambian copperbelt. Berkeley, University of California Press.

Fischer, J. L. (1958). "Social influences on the choice of a linguistic variant." Word 14: 47-56.

Hebdige, D. (1984). Subculture: The Meaning of Style. New York, Methuen.

Hill, J. H. (1993). "Hasta la vista, baby: Anglo Spanish in the American Southwest." Critique of Anthropology 13: 145-76.

Irvine, J. (1979). "Formality and Informality in Communicative Events." American Anthropologist 81(4): 773-790.

Irvine, J. T. and S. Gal (2000). Language ideology and linguistic differentiation. Regimes of language: Ideologies, politics, and identities. P. V. Kroskrity. Santa Fe NM, SAR Press: 35-83.

Labov, W. (1963). "The Social Motivation of a Sound Change." Word 18: 1-42. 
Labov, W. (1966). The Social Stratification of English in New York City. Washington, DC, Center for Applied Linguistics.

Labov, W. (2000). The anatomy of style shifting. Stylistic variation in language. P. Eckert and J. Rickford. Cambridge, Cambridge University Press.

Lave, J. and E. Wenger (1991). Situated Learning: Legitimate Peripheral Participation. Cambridge, Cambridge University Press.

LePage, R. B. and A. Tabouret-Keller (1985). Acts of Identity. Cambridge, Cambridge University Press.

Ochs, E. (1991). "Indexing gender". Rethinking Context. A. Duranti and C. Goodwin. Cambridge, Cambridge University Press.

Okamoto, S. (1995). "Tasteless" Japanese: Less "feminine" speech among young Japanese women. Gender articulated: Language and the socially constructed self. K. Hall and M. Bucholtz. New York and London, Routledge: 297-325.

Rickford, J. R. and R. J. Rickford (2000). Spoken Soul: The Story of Black English. New York, John Wiley and Sons.

Silverstein, M. (1976). Shifters, linguistic categories, and cultural description. Meaning in anthropology. K. Basso and H. A. Selby. Albuquerque, University of New Mexico Press: 11-56.

Trudgill, P. (1974). The Social Differentiation of English in Norwich. Cambridge, Cambridge University Press.

Wenger, E. (2000). Communities of Practice. New York, Cambridge University Press.

Wolfram, W. (1969). A Sociolinguistic Description of Detroit Negro Speech. Washington DC, Center for Applied Linguistics.

Wolfram, W. and N. Schilling-Estes (1996). On the social basis of phonetic resistance: The shifting status of Outer Banks /ay/. Sociolinguistic variation: Data, theory and analysis. J. Arnold, R. Blake, B. Davidson, S. Schwenter and J. Solomon. Stanford CA, CSLI Press.

Zhang, Q. (2001). Changing economics, changing markets: A sociolinguistic study of Chinese yuppies. Linguistics. Stanford CA, Stanford University. 